\title{
Mathematics support for science: a reflection of a blended and online development project
}

Shazia Ahmed, Learning Enhancement \& Academic Development Service, University of Glasgow, Glasgow, UK. Email: Shazia.Ahmed@glasgow.ac.uk

Beth Paschke, School of Chemistry, University of Glasgow, Glasgow, UK. Email: Beth.Paschke@glasgow.ac.uk

Sue Milne, School of Chemistry, University of Glasgow, Glasgow, UK. Email:

Sue.Milne@glasgow.ac.uk

Niall Barr, Information Services, University of Glasgow, Glasgow, UK. Email:

Niall.Barr@glasgow.ac.uk

\section{Abstract}

The diverse range of backgrounds that students bring to university has many advantages, but also some challenges such as a wide range of mathematical experience and ability. A particular issue identified by staff teaching mathematics to the Science Fundamentals cohort was lack of engagement due to the material presented being too easy or too difficult, with the main concerns directed towards students who are weak at mathematics and others who lack some of the basic skills necessary for a successful undergraduate experience at Glasgow.

Our experience from the Science Fundamentals course is that traditional lectures are a poor way to motivate the weaker students and the more collaborative models of teaching such as online and blended learning may be more appropriate. Following a two-year project, a suite of online resources was developed to supplement course material; students completed a 'Mathematics Confidence Test' to determine the level of support required and the number of mathematics lectures was cut down and replaced with tutorials aimed at the weaker students.

We will discuss our experiences of running this project, reflect on feedback and discuss further plans for supporting the Science Fundamentals cohort in subsequent years.

Keywords: Mathematics, chemistry, online learning, Moodle, QTI.

\section{Background}

Confidence and fluency in mathematics are necessary qualities for graduates across the whole range of science subjects. Mathematics is crucial to explore demanding new scientific concepts, to quantify observations accurately and for presenting results in science.

The University of Glasgow prides itself on accepting students from a diverse range of backgrounds into its Science programmes. Of particular concern are students who are weak at mathematics and others who lack some of the basic skills necessary for a successful undergraduate experience at Glasgow.

With the University operating on a college-entry system, undergraduates pursue three subjects in their first year of study. Currently, either Chemistry 1 or Science Fundamentals make up one of the compulsory course choices for Life Sciences students. Science Fundamentals is a two-semester course (administered by the School of Chemistry) consisting of Chemistry, Physics, Mathematics and Statistics. Students in this course bring a very wide range of mathematical experience with them: some may be studying level 1 Mathematics as one of their three subjects whereas others may have studied a minimal amount of mathematics some time ago. A particular issue identified by staff teaching mathematics to this cohort was lack of engagement due to the material presented being 
too easy or too difficult. Our experience has shown that traditional lectures are a poor way to enhance the mathematical skills of these students and the more collaborative models (Swan, 2014) of teaching such as online and blended learning may be more appropriate.

Following a successful application to the University of Glasgow's Blended Learning and Online Development (BOLD) funding scheme, this two-year project aimed to combine the School of Chemistry's ongoing plans for mathematical support provision to early years, whilst at the same time, addressing the ongoing challenges encountered with the teaching of mathematics to the Science Fundamentals cohort. The development of a suite of support resources was planned to be largely delivered online to support the learning and revision of suitable concepts. In addition to these resources, students requiring additional support were to be identified and provided with further focussed support through tutorials (O'Brien and Bedford, 2012).

\section{Year one of the project}

An initial consultation with Chemistry and Mathematics staff involved in the teaching of the course was undertaken, and a complete overhaul of the mathematics component of the Science Fundamentals course was planned. The Mathematics Support Adviser had an insight into common difficulties experienced by students, and these were considered when planning the course content.

A research assistant (RA) was recruited to create a new online course on Moodle (https://moodle.org). The existing course content was reviewed and much of it was reused but presented in a more user-friendly format. The Lesson function in Moodle was utilised to break the material up into manageable chunks. In addition, external links to other resources, mainly MathCentre (http://www.mathcentre.ac.uk), were included.

Advice regarding technical and design elements was sought from learning technologists, and it was recommended that we purchase a Wacom Cintiq graphics tablet to create Khan Academy-style video tutorials to supplement the Moodle lessons. In-house software, DTTPresent (Barr, 2017) and Camtasia were used to create the video tutorials.

Mathematics quizzes were created by the RA which provided the students with randomised questions, allowing them to practise and improve their skills. Technical information about the elearning system can be found in the Appendix and links are available in the References below.

The course was presented such that students could either start from the beginning and work their way through all the material or dip into the topics they wished to work on. Each section consists of some exposition material, worked examples, video tutorials and randomised questions that could be used for practise as often as needed. Some feedback was provided by students regarding the content and layout of the course, which was used to further improve the Moodle resource.

\section{Year two of the project}

The new course was rolled out in September 2017. At the first lecture, the class was given a Maths Confidence Test and the scores were used to identify the level of support required by the students. Previously, two mathematics lectures a week had been timetabled for the six-week long Mathematics block for the Science Fundamentals class. As part of the new course, one lecture per week was replaced with an optional tutorial session. Based on the results of the mathematics confidence test, students were invited to either attend all tutorials or drop in to the sessions as required. For those students with a strong mathematical background, no attendance was required. The whole cohort was referred to the Moodle course for reference and revision as needed. In addition, mathematics support through LEADS was promoted and on offer throughout the year. 
During the academic year, the resource was monitored regularly and iteratively enhanced as necessary. Any feedback received from staff or students was considered and used for making improvements to the resource.

\section{Feedback}

The optional tutorials were very well-attended all year, and feedback was collected at the end of both semesters.

\subsection{Semester one feedback}

In semester one, questionnaires were given only to students attending the final tutorial session. Good feedback was received overall. A selection of responses is listed below:

- I have found maths tutorials useful: $44 \%$ strongly agreed, $47 \%$ agreed, $9 \%$ neutral;

- I would prefer more maths lectures instead of tutorials: $0 \%$ strongly agreed; $3 \%$ agreed, $18 \%$ neutral, $49 \%$ disagreed, $30 \%$ strongly disagreed;

- I feel confident tackling the maths course content: $18 \%$ strongly agreed; $42 \%$ agreed, $30 \%$ neutral, $6 \%$ disagreed, $4 \%$ strongly disagreed.

Comments include:

- "I found tutorials extremely helpful as they gave you a chance to work through material and ask for help one to one when you needed it"

- "Loved the tutorials great idea to do more practice and ask questions the confidence test is a great idea please have it for 2nd semester"

\subsection{Semester two feedback}

In semester two, the whole class was surveyed, not just those who attended the tutorials, and the following feedback was received:

- I have found maths tutorials useful: $26 \%$ strongly agreed, $32 \%$ agreed, $34 \%$ neutral;

- I would prefer more maths lectures instead of tutorials: $7 \%$ strongly agreed; $13 \%$ agreed, $27 \%$ neutral, $35 \%$ disagreed, $18 \%$ strongly disagreed;

- I feel confident tackling the maths course content: $22 \%$ strongly agreed; $41 \%$ agreed, $23 \%$ neutral, $11 \%$ disagreed, $3 \%$ strongly disagreed.

Comments received included:

- "Well rounded maths course that ticks all the boxes for this level of science"

- "I like the structure, I'm confident with the material so I liked being able to not go to tutorials"

We were able to interview a student who was repeating the year, which meant she had experienced both versions of the course. She said "It [the course] was a hundred times better. There was so much more support this year. The notes and examples were better, and the lecturer was very good. Last year two lectures in a week were too much sometimes. If I didn't understand material from the first lecture, I felt overwhelmed at the second one. Having the tutorial was good. It meant I could talk to other students, work through examples and get help if I needed it. The Moodle course was very useful. I liked being able to dip in and out. The questions were good because I could keep trying out examples as many times as I needed to. This felt like the course was maths for science rather than maths for the sake of it". 


\subsection{Preliminary reflections from teaching staff}

The number of lectures was halved, and the continuous assessment was more rigorous, but the results indicated no drop in performance. In fact, Physics scores have showed some improvement.

Staff were pleased with the level of attendance at the optional sessions: $40 \%$ attendance in semester 1 and $32 \%$ in semester 2 . It was generally felt that the modified course had been successful. The students appreciated having a tutorial session where they could consolidate their knowledge and skills, and the more confident students were happy to attend just the lecture. The scores from the Mathematics Confidence Test were used more extensively to target support during the second year of running the course.

\section{Appendix}

The software used to deliver the QTI questions and tests is QTIWorks (Milne et al, 2013), an opensource system developed at the University of Edinburgh. QTIWorks supports IMS QTI v2.1 questions and tests, as well as some extensions to QTI specifically for Mathematics. The Maxima Computer Algebra System (http://maxima.sourceforge.net) is used to provide support for evaluation of algebraic expressions.

To provide a near seamless link between the Moodle Virtual Learning Environment (VLE) and QTIWorks they are linked using IMS LTI, a simple single sign-on protocol designed for educational tools, which also supports the return of marks to the Moodle gradebook. As LTI is a widely supported standard the same technique can be used to link to QTIWorks from other popular VLEs such as Blackboard.

Documentation and source code can be found at https://github.com/davemckain/qtiworks.

\section{References}

Barr, N.S.F., 2017. DTTPresent. University of Glasgow. Available at: https://github.com/niallb/DTTPresent [Accessed 11 March 2019].

Milne, S., Barr, N., and McKain, D., 2013. QTI Delivery Integration Final Report. Available at: http://jiscdesignstudio.pbworks.com/w/file/fetch/66081677/QTIDIFinalReport Final.doc [Accessed 11 March 2019].

O'Brien, G., and Bedford, S., 2012. Small group work in large Chemistry classes: workshops in first year Chemistry. Aiming for Excellence in STEM Learning and Teaching: Proceedings of STEM Annual Conference 2012 (pp.1-10). Available at: https://ro.uow.edu.au/smhpapers/952 [Accessed 11 March 2019].

Swan, M., 2014. Collaborative Learning in Mathematics. Available at: https://doc.uments.com/dcollaborative-learning-in-mathematics.pdf [Accessed 11 March 2019]. 